\title{
Effects of an aversive CS+ and CS- under deprivation upon successive classical appetitive and aversive conditioning
}

\author{
BRUCE K. BROMAGE and MICHAEL J. SCAVIO, JR. \\ California State University, Fullerton, California 92634
}

\begin{abstract}
Rabbits under high or moderate water deprivation received in Stage 1 either paired (CS+), unpaired (CS-), or no-tone/shock presentations, with the pairings being appropriate for nictitating membrane conditioning. In Stage 2 , all groups were given paired tone and water deliveries for jaw-movement conditioning, while, in Stage 3, all group received the tone and shock paired together for membrane conditioning. In Stage 2, the previously established aversive CS+ suppressed jaw-movement conditioning under high deprivation, and membrane CR decrements were directly related to deprivation. Also in Stage 2, the aversive CS - raised jaw-movement conditioning under moderate deprivation. In Stage 3, membrane CR performance immediately returned in the aversive CS+ group. For the other groups, conditioning was faster under high, relative to moderate, deprivation; however, the initial membrane $\mathrm{CR}$ occurrence required more trials if unpaired presentations were used in Stage 1. These results suggest that CSs can acquire both opponent-process and associative effects expressed according to the prevailing training conditions.
\end{abstract}

The Pavlovian mediation of instrumental performance constitutes one of the major principles of modern learning theory. Hull (1931) originally stated that the operations of classical conditioning are necessarily implied in any instrumental conditioning situation. Local cues, functioning as CSs, become paired with the reinforcing event, also serving as a US. The subsequent elicitation of mediating effects by the situational CSs then provides feedback control over the course of instrumental responding.

Despite the wide theoretical acceptance of the mediational principle (cf. Mowrer, 1960; Rescorla \& Solomon, 1967; Trapold \& Overmier, 1972), contemporary theorists have disagreed on how mediation is accomplished. Several researchers (e.g., Gray, 1971; Konorski, 1967; Miller, 1963; Rescorla \& Solomon, 1967) have offered an opponent-process interpretation in which it is assumed that appetitive and aversive incentive motivational systems exert mutually antagonistic influences upon each other's strength. Consequently, excitation in one system, which occurs when an appropriate reinforcing event is received, results in the energization of behavior preceding the reinforcing event and the reflexive

This research was supported by a DAC student research grant to the first author (B.K.B.) and a Friends of the State University award to the second author (M.J.S.). The authors wish to thank Robert T. Ross and Debra A. Branson who aided in the execution of the experiment. Requests for reprints should be addressed to: M. J. Scavio, Department of Psychology, California State University, Fullerton, California 92634. inhibition of behavior supported by the opposite affective system. The final assumption is that the reciprocal effects of reinforcers can be acquired by CSs through classical conditioning operations which are contained in instrumental conditioning situations.

Other investigations (e.g., Fowler, Fago, Domber, \& Hockhauser, 1973; Ghiselli \& Fowler, 1976; Overmier \& Schwarzkopf, 1974; Trapold \& Overmier, 1972) have postulated an "associative" account of mediation. Their position emphasizes that the various classical conditioning operations embedded within instrumental conditioning situations establish the CS with general signaling properties for the delivery of reinforcement. The informational value of CSs then serves to instigate behavior appropriate for the conditions of reinforcement. Moreover, the associative position stresses that the acquisition of general signaling properties is not modified by the hedonic quality of the reinforcing event. In contrast, the opponent-process view is predicated upon the hypothesis that the affective nature of reinforcers is transferred to the CS in order to control behavior. Consequently, the associative view is reminiscent of Lawrence's (1949) acquired distinctiveness of cues hypothesis inasmuch as both positions maintain that stimuli acquire alerting functions due to their past correlations with reinforcement.

Researchers have usually relied upon classicalinstrumental transfer designs to supply evidence regarding the nature of Pavlovian mediation (cf. Gormezano \& Kehoe, 1975; Rescorla \& Solomon, 
1967; Trapold \& Overmier, 1972). But Pavlovian mediation may also be examined by strictly classical conditioning transfer designs. Konorski and Swejkowska (1956), utilizing dog preparations, pioneered the development of such designs; more recently, Scavio (1974) combined the rabbit nictitating membrane (Gormezano, Schneiderman, Deaux, \& Fuentes, 1962) and jaw-movement (Smith, DiLollo, \& Gormezano, 1966) conditioning procedures to provide another transfer alternative. In classical conditioning transfer designs, mediational effects are directly evaluated by changes in CR performance; however, in classical-instrumental transfer designs, the nature of mediation is inferred from changes in instrumental behavior with CR measures not usually taken.

In Scavio's (1974) previous experiment, separate groups of rabbits, restricted to $90 \mathrm{ml}$ of water (moderately high deprivation) for each day of the study, were given, in Stage 1, either paired or unpaired tone-CS and shock-US presentations, respectively (with the CS and US pairings appropriate for membrane conditioning). Another group received no stimulus presentations but was simply confined in the conditioning apparatus for the period of time required to administer training to the other groups. In Stage 2, with the shock-US removed, all groups obtained tone-CS and water-US pairings for jaw-movement conditioning. The Stage 2 results indicated that, relative to unpaired and no stimulus presentations, prior CS and shock-US pairings retarded the development of the jaw-movement CR. Moreover, membrane CR measures were taken during jaw-movement conditioning and revealed that membrane CR strength for the paired group, relative to appropriate control groups, decremented at a more rapid rate than extinction. These results are supportive of the opponent-process interpretation of mediation.

In the present experiment, Scavio's original design has been expanded to include a high vs. moderate water-deprivation manipulation and a third stage in which all groups received tone-CS and shock-US pairings for membrane conditioning. These additions allowed for greater flexibility in testing predictions derived from the opponent-process and associative interpretations of mediation.

For Stage 1 of this study, the opponent-process view does not expect deprivation to have any appreciable effect upon membrane conditioning, since the receipt of the water reinforcement under the drive condition would theoretically be necessary to induce excitation in the appetitive motivational system. Without the excitation in the appetitive system, there can be no reciprocal inhibitory influence exerted upon the aversive motivational system. The associative positions are moot regarding the effects of deprivation on membrane conditioning. If anything, increased appetitive drive might produce greater vigilance for the $\mathrm{CS}$ and shock-US contingency, with the consequence that membrane conditioning rate would be augmented.

For Stage 2, the opponent-process view predicts that the prior CS and shock-US pairings should interfere with jaw-movement conditioning, since the acquired aversive quality of the $\mathrm{CS}+$ is incompatible with the appetitive effects of the water-US. However, the magnitude of the negative transfer effect should be reduced as deprivation increases, since greater thirst should allow the water-US to have correspondingly more excitatory impact upon the appetitive motivational system. Therefore, the aversive properties of the CS + should be more quickly counteracted through the reciprocal inhibition mechanism allowing then for the faster acquisition of the appetitive jaw-movement CR. The greater reciprocal inhibition under high deprivation also should lead to larger deficits in membrane CR performance during jaw-movement training. Finally, several opponent-process theorists (e.g., Gray, 1971; Konorski, 1967; Rescorla \& Solomon, 1967) hold that stimuli which signal the absence of an aversive event acquire appetitive motivational properties. Therefore, unpaired CS and shock-US deliveries in Stage 1 should promote jaw-movement conditioning, since the affective nature of the CS - is assumed to be compatible with the water-US. In contrast, the associative position clearly expects that the prior establishment of the aversive CS + should increment jaw-movement conditioning, since this CS enters Stage 2 with signaling properties for the presence of reinforcement already established. However, the aversive CS - should interfere with jaw-movement conditioning since this stimulus predicts the absence of reinforcement.

For Stage 3, Konorski's theory (1967, p. 339) expects that the rapid reacquisition of the membrane CR should occur for the paired groups of Stage 1 . Although Konorski adopted an opponent-process view of motivation, his general behavioral theory has also attempted to incorporate associative factors involved in conditioning. His position would maintain that the CS + still retains the capacity to elicit the membrane $\mathrm{CR}$ even though opponent-process inhibition should block its performance during jawmovement conditioning. Consequently, when the shock-US is reintroduced with the CS and the waterUS is removed in Stage 3, membrane CR performance should resume at its Stage 1 conditioning strength.

The other Stage 1 unpaired and no-training groups receive membrane conditioning for the first time in Stage 3. If unpaired CS and shock-US presentations in Stage 1 have carry-over effects into Stage 3, then 
the associative position would predict that the CSshould retard the acquisition of the membrane CR. The associative position makes no clear predictions about how deprivation might affect membrane acquisition. However, if increased deprivation produces greater arousal allowing the CS in Stage 2 to become a more effective signal for the presence of reinforcement and the strength of the signaling function generalizes to Stage 3, then membrane CR acquisition rate would positively vary with deprivation. On the other hand, the opponent-process view expects an inverse relationship between deprivation and membrane $C R$ acquisition rate. The CS should acquire correspondingly stronger appetitive effects of the water-US in Stage 2 jaw-movement conditioning as deprivation is increased. Therefore, the stronger appetitive properties provide more inhibition against the establishment of the aversive membrane CR.

\section{METHOD}

\section{Subjects}

The subjects were 36 male and female New Zealand albino rabbits (Oryctolagus cuniculus), about 90 days old at the beginning of the experiment.

\begin{abstract}
Apparatus
Six conditioning chambers were fabricated from legal-sized file cabinets, with each ventilated chamber containing a stimulus panel which held two $24-\mathrm{V} \mathrm{dc}, 10-\mathrm{W}$ lamps mounted behind diffusion glass for interior illumination and a $6.35-\mathrm{cm}$ Quam audio speaker. Plexiglas boxes with variable backplates and yoke collars were used to restrain the rabbit during training.

Nictitating membrane and jaw-movement responses were recorded by means of $10-\mathrm{k} \Omega$ Giannini microtorque potentiometers which converted physical movement into linear voltages changes. These changes were amplified and fed into an analog-to-digital converter of a PDP- 12 computer for analysis. During training, both potentiometers were mounted on a muzzle device which was securely locked to a ring looped over the rabbit's pinnae. The rabbit's right-side potentiometer recorded jaw-movement responding by having a counterbalanced piano-wire rod pass through a stainless steel wound clip placed in the lower mandible and fastened to the rotary system of the potentiometer. The left-side potentiometer recorded nictitating membrane movement by hooking a counterbalanced rod to a suture placed in the left membrane. In addition, the analog-to-digital inputs representing membrane or jaw-movement responding for each subject were stored on each trial and then displayed on the computer's cathode ray tube during the intertrial interval to verify that artifacts were not contaminating computer interpretation of the data. The CS was a $500-\mathrm{msec}, 1,000-\mathrm{Hz}$ tone of $80 \mathrm{~dB}\left(\mathrm{re} 20 \mu \mathrm{N} / \mathrm{m}^{2}\right)$ superimposed on a 72-dB white-noise field. The US for membrane conditioning was a $50-\mathrm{msec}, 4-\mathrm{mA}, 60-\mathrm{Hz}$ electrical shock delivered through alligator clips attached to stainless steel wound clips embedded in the skin $10 \mathrm{~mm}$ apart and $15 \mathrm{~mm}$ behind the left eye. The US for jaw-movement conditioning was a $300-\mathrm{msec}$, $1-\mathrm{ml}$ squirt of water delivered directly into the oral cavity through a polyethylene cannula implanted in the left cheek. The water entered the conditioning chamber from a pressurized (5-psi) reservoir via Tygon tubing terminating with a blunted hypodermic needle. The presentation of the stimuli as well as the recording of the responses were under PDP-12 computer control. The necessary software is described elsewhere (Bissell \& Scavio, 1974).
\end{abstract}

\section{Procedure}

Two days after arrival, each rabbit received a suture in the left membrane made with 00 monofilament nylon thread. Next, the rabbit was anesthetized with ether and a polyethylene cannula was placed in the left cheek. Three days later, each group of six rabbits (three males and three females, randomly assigned) was placed on a water-deprivation schedule which limited drinking to either $60 \mathrm{ml}$ (high deprivation) or $120 \mathrm{ml}$ (moderate deprivation) of water in the home cage for each day of the experiment. These deprivation levels were selected on the basis of Mitchell and Gormezano's (1970) study, which found a positive relationship between deprivation and jaw-movement CR strength. (Average daily ad-lib water intake for 90 -day-old rabbits is about $300 \mathrm{ml}$.) On the 7 th day following anesthetization, all groups received a 40 -min adaptation period in the conditioning chambers with no stimuli being presented. On the next day, groups were assigned to Stage 1 training conditions.

In Stage 1, which lasted 3 successive days, Groups P-60 and P-120 (paired groups) received, on each day, 80 paired presentations of the tone-CS and shock-US while limited to 60 and $120 \mathrm{ml}$ of daily water, respectively. Groups U-60 and U-120 (unpaired groups) received, on each day, 80 unpaired presentations of the tone-CS and shock-US while under the appropriate deprivation regime. For the unpaired groups, the ordering of tone and shock was randomized with the restriction that in each block of 10 stimulus events an equal number of tones and shocks occur with no more than three successive presentations of the same event. Thus, the presentations of tone and shock for Groups U-60 and U-120 were given in an explicitly unpaired manner which, according to Rescorla (1967), renders the CS as a predictor of the absence of the US. Groups N-60 and N-120 (no-training groups), on the appropriate deprivation schedules, received neither the tone nor the shock but were simply confined in the chambers for the period of time necessary to administer training to the paired and unpaired groups.

In Stage 2, which began on the day following the completion of Stage 1 , the shock-US was eliminated and all groups were given 30 paired presentations of the tone-CS and water-US for jawmovement conditioning on each of 7 successive days. Both membrane and jaw-movement responses were recorded. (Previous pilot work had indicated that jaw-movement CRs are not concomitantly acquired during membrane conditioning and vice versa with the procedures used in this experiment.)

In Stage 3, which started on the day following the conclusion of Stage 2, all groups received 80 paired presentations of the tone-CS and shock-US for membrane conditioning on each of 3 successive days. The water-US was not employed in Stage 3.

For the paired groups in Stage 1 and all groups in Stages 2 and 3, the CS-US interval for conditioning was $500 \mathrm{msec}$. The intertrial interval for the paired groups in Stage 1 and all groups in Stage 3 was randomized at values of 50 and $70 \mathrm{sec}$, with a mean of $60 \mathrm{sec}$. In Stage 2, the intertrial interval was randomized at values of 60,70 , and $80 \mathrm{sec}$ with a mean of $70 \mathrm{sec}$. For the unpaired groups in Stage 1, the interevent interval was randomized at values of 25 and $35 \mathrm{sec}$, with a mean of $30 \mathrm{sec}$. Membrane and jaw-movement extension of at least $1 \mathrm{~mm}$ occurring during the CS-US interval on paired trials, $500 \mathrm{msec}$ from tone onset on unpaired trials, and a corresponding 500 -msec time interval for the no-training groups in Stage 1, were recorded as CRs.

\section{RESULTS}

\section{Stage 1 Membrane Conditioning}

The unpaired (U-60 and U-120) and no-training (N-60 and N-120) groups did not show more than $4 \%$ membrane responses on any of the Stage 1 days. As expected, the paired (p-60 and $P-120$ ) groups evidenced acquisition of the membrane $C R$, and on Day 3 both groups achieved a stable CR rate of $95 \%$ on the conditioning trials. An analysis of variance 
upon percentage of membrane CRs in blocks of 20 trials over the Stage 1 days for the two paired groups did not reveal any reliable Group difference. However, significant Days, $F(2,20)=59.38$, $\mathrm{p}<.01$, Blocks, $\mathrm{F}(3,30)=18.13, \mathrm{p}<.01$, and Days by Blocks interaction, $F(6,60)=5.31, p<.01$, effects were found. Thus, for both Groups P-60 and $\mathrm{P}-120$ the rate of membrane $\mathrm{CR}$ acquisition was more rapid earlier as compared to later in training when CR levels began to reach asymptotic strength. A similar analysis of variance for the unpaired and no-training groups failed to reveal any reliable Group or Training Session differences, which corroborated the observation that membrane response levels remained uniformly minimal during Stage 1 .

\section{Stage 2 Jaw-Movement Conditioning}

Figure 1 shows the percentage of jaw-movement CRs given by each group on the conditioning days of Stage 2. A comparison of Groups N-60 and $\mathrm{N}-120$, which reveals the effects of water deprivation uninfluenced by prior paired or unpaired CS and shock-US presentations, indicates the expected positive relationship between deprivation and jawmovement conditioning. In contrast, the jawmovement CR performances for the Stage 1 paired and unpaired groups show a variable pattern over the training days. On Days 1 through 3, no clear acquisition differences exist for the paired and unpaired groups, although Group P-120 showed the highest $C R$ rate on Day 1, which then decreased slighly on adjacent days of training. However, on Days 4 through 7, differences begin to emerge in that the high-deprivation groups, $\mathrm{P}-60, \mathrm{U}-60$, and $\mathrm{N}-60$, averaged a greater $C R$ rate $(\bar{X}=82 \%$ ) compared to the moderate-deprivation groups, P-120, U-120, and $\mathrm{N}-120(\overline{\mathrm{X}}=69 \%)$. In addition, the Stage 1 training conditions also appeared to influence the CR asymptotes. Groups U-60 and U-120, which had received unpaired $C S$ and shock-US deliveries, averaged the highest $C R$ level $(\overline{\mathrm{X}}=86 \%)$ on the last 4 days; Groups N-60 and N-120, which had no stimulus presentations, were intermediate $(\bar{X}=75 \%)$; and Groups P-60 and P-120, which had paired CS and shock-US trials, were lowest $(\bar{X}=67 \%)$. A further examination of the individual groups over the last 4 days suggests an interaction between Deprivation and Stage 1 Training Conditions. Under high deprivation, Groups U-60 ( $\bar{X}=91 \%)$ and N-60 $(\overline{\mathrm{X}}=87 \%)$ performed similarly and were above the CR level of Group P-60 ( $\bar{X}=70 \%)$. However, under moderate deprivation, Group U-120 ( $\overline{\mathrm{X}}=$ $81 \%$ ) responded above the similar levels of Group P-120 ( $\bar{X}=63 \%)$ and Group N-120 ( $\bar{X}=$ $64 \%$ ).

The effects of water deprivation upon jawmovement conditioning uncomplicated by prior paired or unpaired tone-CS and shock-US deliveries were assessed by conducting an analysis of variance for Groups N-60 and N-120 upon percentage of jawmovement CRs in blocks of 10 trials over the conditioning days. Significant values were found for Groups, $F(1,10)=8.91, p<.05$, Days, $F(6,60)$ $=15.75, \mathrm{p}<.01$, Blocks, $\mathrm{F}(2,20)=8.73, \mathrm{p}<.01$, and the Days by Blocks interaction, $F(12,120)=$ $5.96, \mathrm{p}<.01$. These results confirmed that a positive relationship exists between deprivation and jawmovement conditioning, with the interaction indicating greater between and within-session acceleration in CR acquisition earlier in training.

Given that the initial acquisition rates do not predict accurately asymptotic CR levels for the paired and unpaired Stage 1 training groups, separate analyses of variance were conducted upon percentage of jaw-movement CRs in blocks of 10 trials for Days 1 through 3 and then for Days 4 through 7 for all groups. The analysis for Days 1 through 3 revealed significant effects only for Days, $F(2,60)$ $=14.53, \mathrm{p}<.01$, and Blocks, $F(2,60)=4.53$, $\mathrm{p}<.05$, denoting the general tendency for betweenand within-session CR acquisition for all groups. The analysis for Days 4 through 7 resulted in significant effects for Deprivation, $F(1,30)=6.78, p<.02$, substantiating a positive relationship between thirst and jaw-movement CR strength during the asymptotic phase of Stage 2; for Stage 1 Training Conditions, $F(2,30)=5.24, p<.02$, verifying that the prior conditioning history of the CS influenced the establishment of jaw-movement CR asymptotes; for Days, $F(3,90)=5.56, p<.01$, as well as Blocks, $F(2,60)$ $=22.23, \mathrm{p}<.01$, indicating between- and withinsession fluctuations in CR strength; and for an inter-

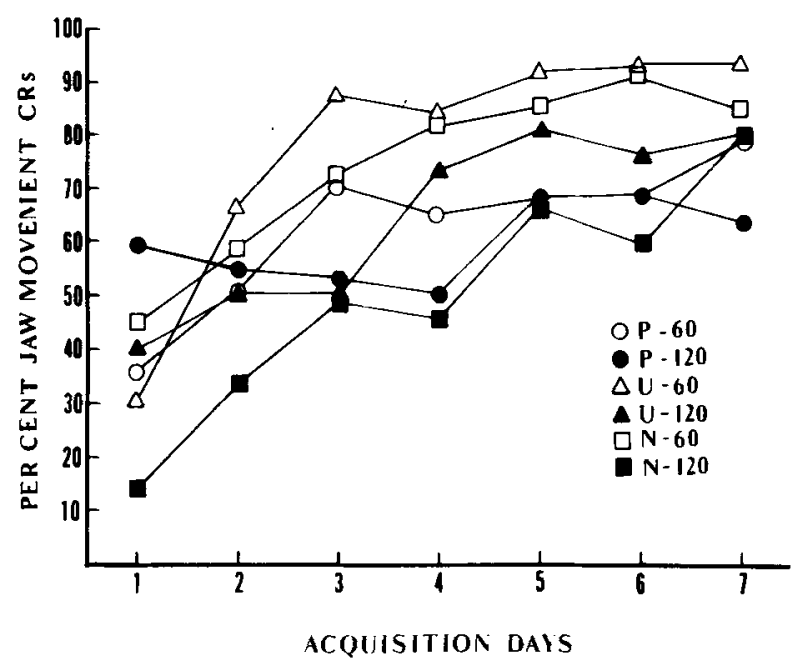

Figure 1. Mean percentage of jaw-movement CRs plotted over the training days in Stage 2 for all groups ( $P=$ paired; $U=$ unpaired; and $N=$ no training) under high $(60 \mathrm{ml})$ and moderate $(120 \mathrm{ml})$ water deprivation. 
action between Deprivation and Stage 1 Training Conditions, $\mathrm{F}(2,30)=3.48, \mathrm{p}<.05$, showing that the effects of prior training were dependent upon deprivation level. This interaction effect was further evaluated by computing separate analyses of variance upon percentage of jaw-movement CRs collapsed over Days 4 through 7 for the groups in the high- and moderate-deprivation conditions followed by Newman-Keuls comparison tests. The analysis for high deprivation revealed significant Group differences, $F(2,15)=4.38, p<.05$, and the subsequent comparison test showed that the mean percentage of CRs for Group P-60 was reliably below (ps < .05) the levels attained by Groups U-60 and $\mathrm{N}-60$, with no difference between the latter two groups. The analysis for moderate deprivation also resulted in significant Group differences, $F(2,15)$ $=3.88, \mathrm{p}<.05$, with the comparison test showing Group U-120 to be superior (ps $<.05$ ) to Groups P120 and $N-120$, with no difference between the latter two groups.

Figure 1 also shows that Group P-120 had an unusually high rate of jaw-movement CRs compared to the other moderate-deprivation groups on the 1st day of training. In contrast, all the highdeprivation groups had similar 1st day CR percentages. An analysis of variance conducted upon percentage of jaw-movement CRs on the 1st day for the moderate-deprivation groups yielded a reliable Groups effect, $F(2,15)=3.94, p<.05$; and a Newman-Keuls test found the performance of Group P-120 to be superior $(p<.05)$ to that of Group N-120, with Group U-120 not being different from the previous two groups. A similar analysis of variance for the high-deprivation groups showed no reliable 1st day difference.

\section{Stage 2 Membrane CR Performance}

Figure 2 presents the percentage of membrane CRs for Groups P-60 and P-120 on each of the Stage 2 training days. (Since the other groups did not show membrane CRs, their data were not included in the figure.) The figure reveals that Group P-60 evidenced a greater reduction of membrane CRs than did Group P-120, even though both groups terminated Stage 1 with asymptotic levels of membrane conditioning. Moreover, the absolute decrement in membrane CR performance for Group P-120 over the Stage 2 days was remarkably small. An analysis of variance upon percentage of membrane CRs in 10-trial blocks over the training days found a significant Group difference, $F(1,10)=24.87$, $\mathrm{p}<.01$, supporting the observation that Group P-60 experienced greater membrane $\mathrm{CR}$ deficits during jaw-movement conditioning than did Group P-120. A significant Groups by Days interaction, $F(6,60)$ $=2.61, \mathrm{p}<.05$, was obtained, which corroborated

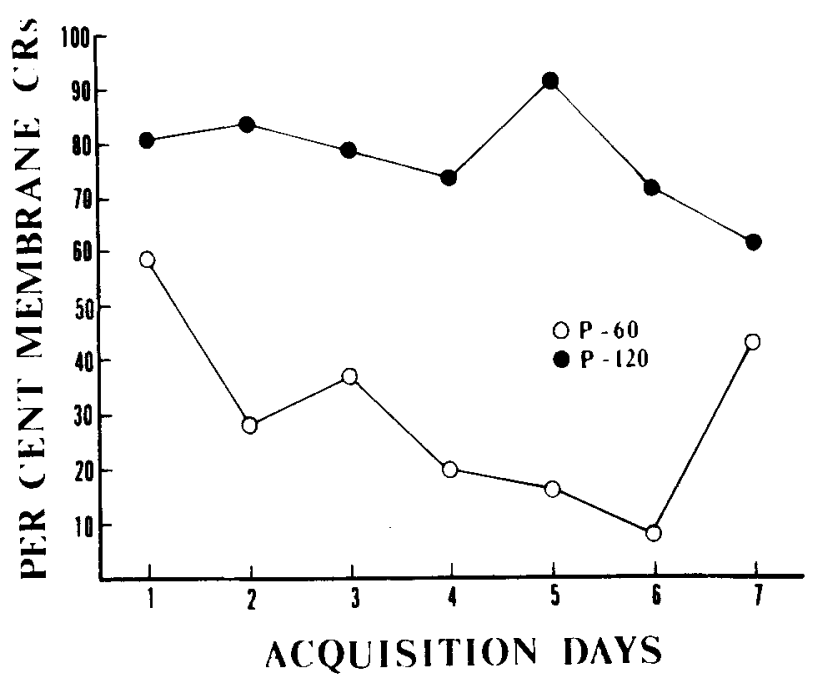

Figure 2. Mean percentage of nictitating membrane CRs plotted over the training days of Stage 2 for the high $(P-60)$ and moderate (P-120) deprivation groups receiving prior $C S$ and shock-US pairings.

that the decrement in membrane $C R$ performance over days was more prominent for Group P-60 than for Group P-120. A significant Blocks effect, $F(2,20)$ $=12.59, \mathrm{p}<.01$, coupled with a Groups by Days by Blocks interaction, $F(12,120)=2.01, p<.05$, meant that the CR performance for Group P-60 observed within daily sessions showed greater fluctuations than that of Group P-120.

Finally, chi-square tests of independence were used to evaluate the possibility that motor rivalry between the membrane and jaw-movement response systems contributed to the Stage 2 transfer effects. According to the independence theorem (Parzen, 1960), if the obtained probability of a joint membrane/jawmovement $C R$ occurrence is predicted by multiplying together the separate obtained probabilities for membrane and jaw-movement CRs, then these two CRs would be defined to be independent events. Chi-square tests, evaluating predicted vs. obtained joint CR occurrences, were calculated on each of the last 4 days of Stage 2 for Group P-60 and then for Group P-120. All chi-square tests yielded nonsignificant outcomes; therefore, the elicitation of either the membrane or jaw-movement $C R$ did not influence the occurrence of the other $\mathrm{CR}$.

\section{Stage 3 Membrane CR Performance}

Figure 3 presents the percentage of membrane CRs for all groups over the Stage 3 training days. The figure shows that both Groups P-60 and P-120 rapidly reacquired the membrane $C R$ and that no subject in these groups needed more than five CS-shock US pairings on Day 1 to return the membrane CR to asymptotic strength. An analysis of variance upon percentage of membrane CRs in blocks of 20 trials 


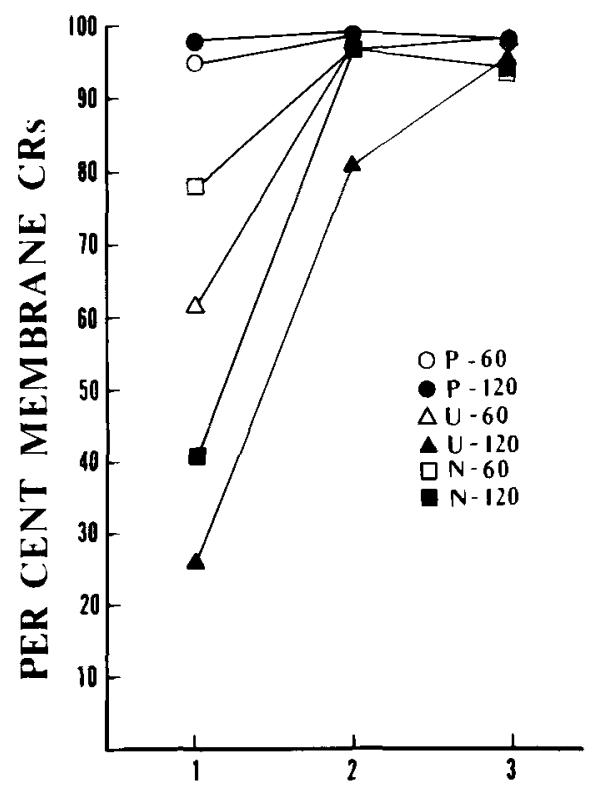

ACQUISITION DAYS

Figure 3. Mean percentage of nictitating membrane CRs plotted over the training days in Stage 3 for all groups $(P=$ paired; $\mathrm{U}=$ unpaired; and $\mathrm{N}=$ no training) under high $(60 \mathrm{ml})$ and moderate $(120 \mathrm{ml})$ water deprivation.

over the Stage 3 days produced no differences in the reacquisition patterns for the two paired groups.

The other groups experienced paired CS and shock-US deliveries for the first time. Acquisition appears to be faster under high deprivation, in that the average performance of Groups U-60 and N-60 $(\bar{X}=70 \%)$ on the 1 st day surpasses the average for Groups U-120 and $\mathrm{N}-120(\overline{\mathrm{X}}=34 \%)$. To a lesser extent, the prior exposure to unpaired CS and shockUS presentations in Stage 1 had carry-over effects, since Groups U-60 and U-120 ( $\overline{\mathrm{X}}=44 \%)$ averaged fewer CRs on the 1 st day than Groups $N-60$ and $\mathrm{N}-120(\overline{\mathrm{X}}=60 \%)$. Computation of the number of trials to the first CR for Groups U-60 $(\bar{X}=24.16)$, $\mathrm{N}-60(\overline{\mathrm{X}}=11.00), \mathrm{U}-120(\overline{\mathrm{X}}=58.83)$, and $\mathrm{N}-120$ $(\bar{X}=29.50)$ also indicated that deprivation and Stage 1 training conditions were related to membrane $\mathrm{CR}$ acquisition. Finally, Figure 3 shows that all groups eventually reached the same CR level on the 3rd day.

An analysis of variance, with moderate- vs. highdeprivation and unpaired CS and shock-US presentations vs. no training in Stage 1 as the dimensions, upon percentage of membrane CRs in 20-trial blocks over the Stage 3 days found a reliable Deprivation effect, $F(1,20)=13.24, p<.01$, which substantiates that $C R$ acquisition was faster for the high deprivation groups. However, Stage 1 Training Conditions produced effects only approaching significance, $F(1,20)$ $=3.12, \mathrm{p}<.07$. Also significant Days, $F(2,40)$
$=65.00, \mathrm{p}<.01$, and Blocks, $\mathrm{F}(3,120)=19.44$, $\mathrm{p}<.01$, effects were coupled with a Days by Blocks interaction, $F(6,120)=13.75, p<.01$, indicating that the rate of $C R$ acquisition was greater earlier in Stage 3 training and slowed as the groups approached asymptotic CR strength.

Another analysis of variance for the moderate and high-deprivation unpaired and no-training groups upon trials to the first $C R$ resulted in significant effects for both Deprivation, $F(1,20)=7.80, p<.02$. and Stage 1 Training, $F(1,20)=4.98, p<.05$. Therefore, the initial appearance of the membrane CR in Stage 3 tended to occur more rapidly under the conditions of high relative to moderate deprivation and no training relative to the receipt of unpaired CSs and shock-USs in Stage 1.

\section{DISCUSSION}

The major results in each stage of this experiment may be summarized and evaluated as follows. In Stage 1 , as expected, membrane $C R$ acquisition occurred only for Groups P-60 and P-120, which were given tone-CS and shock-US pairings. Other groups, receiving either unpaired (U-60 and U-120) or no (N-60 and N-120) CSs and USs, showed no baseline changes in membrane responding. Moderate and high levels of water deprivation, controlled by limiting daily intake to 120 and $60 \mathrm{ml}$, respectively, did not differentially affect membrane conditioning. The failure of thirst to influence membrane conditioning rates is consistent with the opponentprocess view. Without the water-US in Stage 1, the appetitive system could not be excited to produce reciprocal inhibitory effects upon membrane CR acquisition.

In Stage 2, all groups received the tone-CS of Stage 1 now paired with a water-US to allow for jawmovement conditioning. The use of the shock-US was discontinued. Under high deprivation, the Stage 2 transfer results indicated that Group P-60 displayed a decrement in the asymptotic level of jaw-movement conditioning as compared to Groups U-60 and N-60. In contrast, under moderate deprivation, Group P-120 showed transitory facilitation in the acquisition of the jaw-movement CR relative to the performance of Group N-120; and Group U-120 displayed an increment in the asymptote of jaw-movement conditioning as measured against the performances of Groups P-120 and $\mathrm{N}-120$. Also, membrane $\mathrm{CR}$ performance was recorded for Groups P-60 and P-120 during jawmovement conditioning. Losses in membrane CR strength were positively related to deprivation, with the occurrences of jaw-movement and membrane CRs being statistically independent events during the asymptotic phase of jaw-movement training. 
Since the membrane and jaw-movement CR occurrences were found to be independent in this experiment and also in Scavio's (1974) previous study, peripheral motor incompatibility between these response systems is apparently ruled out as the factor controlling Stage 2 transfer effects. Finally, the effects of water deprivation, isolated from those of Stage 1 paired and unpaired CS and shock-US deliveries, upon jaw-movement conditioning were revealed by comparing the performances of Groups N-60 and N-120. A positive relationship between deprivation and $C R$ strength was found which replicates Mitchell and Gormezano's (1970) findings.

The Stage 2 transfer results indicate the importance of water deprivation level in determining the transfer effects of the aversive $\mathrm{CS}+$ upon appetitive jawmovement conditioning. Under high deprivation, the use of the aversive CS + lowered the jaw-movement conditioning asymptote, and membrane $\mathrm{CR}$ strength rapidly dropped. The mutual reductions in jawmovement and membrane $C R$ performances under high deprivation are in agreement with the findings of Scavio (1974), who employed a $90-\mathrm{ml}$ daily water ration; and these data support opponent motivational processes as being responsible for the simultaneous decrements in jaw-movement and membrane CR performances. However, under moderate deprivation, the aversive CS + did not have any negative transfer effects upon jaw-movement conditioning and membrane CR performance during jawmovement conditioning remained high. Therefore, the reciprocal inhibitory mechanism of opponent processses may not have operated. Instead, there was some suggestion that associative signaling properties were present to a limited extent, in that the aversive CS + raised the level of jaw-movement conditioning on the 1st day of training.

These observations regarding the differential effects of deprivation suggest that a threshold level of excitation must be reached in the appetitive motivational system (and presumably in the aversive system) before inhibitory interactions can be expressed. Accordingly, for the present experiment, the threshold model of opponent processes would stress that the high deprivation level, as well as the ration employed in Scavio's (1974) previous study, allowed the water-US to excite the appetitive motivational system above the value required to trigger the reflexive inhibitory interactions with the aversive system. The adoption of the threshold model for opponent processes departs from its traditional theoretical description (cf. Gormezano \& Kehoe, 1975), which maintains that algebraic summation of the opposing motivational strengths determines the final behavioral effects.

Water deprivation also controlled the effects of the aversive CS - in Stage 2. Under moderate (but not high) deprivation, the use of this stimulus enhanced the jaw-movement conditioning asymptote. The opponent-process view expected the positive transfer effect, since an aversive CS - is presumed to acquire appetitive motivational characteristics. Moreover, the opponent-process position could maintain that the additive effects of the aversive $\mathrm{CS}$ - were not apparent under high deprivation, since the amount of excitation in the appetitive motivational system may have approached ceiling levels.

Turning to the Stage 3 results, Groups P-60 and $P-120$ needed only five reacquisition trials to return the membrane CR to asymptotic strength. The unpaired (U-60 and U-120) and no-training (N-60 and $\mathrm{N}-120)$ groups received $\mathrm{CS}$ and shock-US pairings for the first time to allow for membrane CR acquisition; and the results for these groups indicated that high relative to moderate deprivation enhanced membrane conditioning. Additionally, within each deprivation level, a trials-to-first-CR analysis revealed that the unpaired group needed more pairings than the no-training group before the initial $\mathrm{CR}$ was elicited.

The rapid reacquisition of the membrane CR for Groups P-60 and P-120 agrees with the findings of Konorski and Szwejkowska (1956), who reported that an aversive leg-flexion $C R$ in dogs quickly returned despite intervening pairings of the aversive CS with appetitive US. The reacquisition pattern presently observed is especially interesting, since Groups P-60 and P-120 showed substantially different membrane $C R$ performances during jawmovement training. Consequently, the equally rapid reacquisition of the membrane $\mathrm{CR}$ must indicate that the representational strength of the CS-membrane CR connection was not appreciably weakened by the conditioning of the jaw-movement $\mathrm{CR}$ to the same CS. If it were otherwise, then the number of trials needed to restore the membrane CR asymptote should have varied directly with the decrements in membrane responding during jaw-movement training. Konorski's (1967) theory predicts the equally rapid return of the membrane CR for the two paired groups, even though Group P-60 suffered a greater membrane $C R$ loss. The opponent-process inhibition of the membrane CR for Group P-60 would be assumed by Konorski's theory to block the performance of the response without affecting the underlying associative strength. Consequently, when the shock-US is substituted for the water-US, the inhibition is removed which allows for the resumption of membrane $C R$ performance.

The Stage 3 data for the other groups indicate that the effects of water deprivation and prior unpaired CS and shock-US deliveries contributed to membrane $C R$ acquisition in a manner consistent 
with the associative account of mediation (e.g., Fowler et al., 1973; Ghiselli \& Fowler, 1976; Overmier \& Schwarzkopf, 1974; Trapold \& Overmier, 1972). The associative position would explain the faster membrane $C R$ acquisition under high relative to moderate deprivation by first noting the positive relationship between thirst and jaw-movement conditioning in Stage 2. Consequently, high deprivation might have resulted in greater arousal, allowing the CS to become a more salient cue for the presence of reinforcement. Therefore, the augmented membrane $C R$ acquisition is accountable to the transfer from Stages 2 to 3 of a CS with greater distinctiveness as a signal for reinforcement. Since deprivation did not influence Stage 1 membrane conditioning, it would appear that the CS must have excitatory value (acquired in Stage 2) before deprivation can affect membrane $C R$ acquisition. In contrast, the opponent-process view would have predicted that moderate deprivation should have been related to faster membrane $C R$ acquisition, since the appetitive properties of the CS would be weaker under moderate relative to high deprivation. Thus, the strength of the reciprocal inhibition blocking the conditioning of the membrane $\mathrm{CR}$ would be reduced.

The finding, within each deprivation condition, that unpaired CS and shock-US deliveries, compared to no stimulus presentation in Stage 1, added to the number of trials needed for the initial appearance of the membrane $C R$, agrees with the associative view. Apparently, the Stage 1 use of the CS as a predictor for the nonoccurrence of the shock-US provided interference which subtracted from the signaling value of the CS for the presence of the shock-US in Stage 3. The inhibitory effects of prior unpaired $\mathrm{CS}$ and shock-US presentations upon conditioning when these stimuli are subsequently paired together have been observed before (Siegel \& Domjan, 1971). However, the interesting aspect of the present result is that, just as the excitatory effects of the aversive $\mathrm{CS}+$, the inhibitory effects of the aversive CS upon membrane $C R$ performance were retained even though these CSs had presumably acquired appetitive properties during Stage 2 jaw-movement conditioning.

In summary, the results of this experiment demonstrated that aversive excitatory and inhibitory CSs influenced appetitive jaw-movement conditioning in a manner described by a threshold model of opponent processes. However, jaw-movement CR acquisition did not dispel the associative effects of these CSs upon aversive membrane CR performance. Consequently, the present data suggest that CSs are capable of having dual mediational effects, and the affective quality of the US may be an important factor regulating the expression of opponent-process and associative influences. The existence of dual sources of mediation has long been theoretically acknowledged in that Spence (1956) assigned both associative and secondary drive properties to the $r_{g}-s_{g}$ mechanism in the control of instrumental appetitive behavior. However, only recently has any attempt (Soltysik, 1971) been made to provide a theoretical bridge between contemporary associative and opponent-process views of mediation. Briefly, Soltzysik's rapprochement, based upon the principles of Konorski's (1967) theory, claims that different classical conditioning parameters control the acquisition rate and strength of associative and opponent-process mediational effects. Therefore, experimental outcomes which unilaterally support one mediational position over the other may be reflecting how certain variables maximize the expression of the particular mediational effect. Even more recently, Dickinson and Pearce (1977) have presented a thorough review of the evidence favoring opponent-process theory, and their summary shows that not all aversive-appetitive interaction experiments yield results consistent with the opponentprocess interpretation. Accordingly, the principles which explain the dominance of one mediational effect over the other and specify their joint modes of interaction need to be established before the full scope of Pavlovian mediation can be appreciated.

\section{REFERENCES}

Bissell, H. S., \& Scavio, M. J., JR. A minicomputer program for the resolution of response frequency and latency in classical conditioning preparations. Behavior Research Methods \& Instrumentation, 1974, 6, 439-442.

Dickinson, A., \& PeARCe, J. M. Inhibitory interactions between appetitive and aversive stimuli. Psychological Bulletin, 1977, 84, 690-711.

Fowler, H., Fago, G. C., Domber, E. A., \& Hockhauser, M. Signaling and affective functions in Pavlovian conditioning. Animal Learning \& Behavior, 1973, 1, 81-89.

GHiselli, W. B., \& Fowler, H. Signaling and affective functions of conditioned aversive stimuli in appetitive choice discriminations: US intensity effects. Learning and Motivation, 1976, 7, 1-16.

Gormezano, I., \& Kehoe, E. J. Classical conditioning: Some methodological and conceptual issues. In W. K. Estes (Ed.), Handbook of learning and cognitive processes (Vol. 2) Conditioning and behavior theory. Hillsdale N.J: Erlbaum, 1975.

Gormezano, I., Schneiderman, N., Deaux, E. B., \& Fuentes, I. Nictitating membrane: Classical conditioning and extinction in the albino rabbit. Science, 1962, 138, 33-34.

GRAY, J. A. The psychology of fear and stress. New York: McGraw-Hill, 1971.

Hull, C. L. Goal attraction and directing ideas conceived as habit phenomena. Psychological Review, 1931, 38, 487-506.

KoNORSKI, J. Integrative activity of the brain: An interdisciplinary approach. Chicago: University of Chicago Press, 1967.

KONORSKI, J., \& SZWEJKowSKA, G. Reciprocal transformation of heterogeneous conditioning reflexes. Acta Biologiae Experimentalis, 1956, 17, 141-165.

LaWrence, D. H. Acquired distinctiveness of cues: 1. Transfer 
between discriminations on the basis of familiarity with the stimulus. Journal of Experimental Psychology, 1949, 39, 770-784.

Miller, N. E. Some reflections on the law of effect produce a new alternative to drive reduction. In $M . R$. Jones (Ed.), Nebraska Symposium on Motivation (Vol. 11). Lincoln: University of Nebraska Press. 1963.

Mitchell, D. S., \& Gormezano, I. Effects of water deprivation on classical appetitive conditioning of the rabbit's jaw-movement response. Learning and Motivation, 1970, 1, 199-206.

Mowrer. O. H. Learning theory and behavior. New York: Wiley, 1960 .

OVERMIER, J. B., \& SchwarzKopf, K. H. Summation of food and shock based responding. Learning and Motivation, 1974, 5. 42-52.

PARzen, E. Modern probability theory and its applications. New York: Wiley, 1960.

Rescorla, R. A. Pavlovian conditioning and its proper control procedures. Psychological Review, 1967, 74, 71-80.

Rescorla, R. A., \& Solomon, R. L. Two process learning theory: Relationships between Pavlovian conditioning and instrumental learning. Psychological Review, 1967, 74, 151-182.
SCAvio, M. J., JR. Classical-classical transfer: Effects of prior aversive conditioning upon appetitive conditioning in rabbits (Oryctolagus cuniculus). Journal of Comparative and Physiological Psychology, 1974, 86, 107-115.

Siegel, S., \& Doman, M. Backward conditioning as an inhibitory procedure. Learning and Motivation, 1971, 2, 1-11.

Smith, M. C., Dilollo, V., \& Gormezano, I. Conditioning jaw movement in the rabbit. Journal of Comparative and Physiological Psychology, 1966, 62, 479-483.

Soltysik, S. On the homogeneous and heterogeneous transformation of conditioned reflexes: A comment on the Overmier and Payne case of positive transfer. Acta Neurobiologiae Experimentalis, 1971, 31, 401-407.

SPENCE, K. W. Behavior theory and conditioning. New Haven: Yale University Press, 1956.

Trapold, M. A., \& Overmier, J. B. The second learning process in instrumental conditioning. In A. H. Black \& W. F. Prokasy (Eds.), Classical conditioning II: Current theory and research. New York: Appleton-Century-Crofts, 1972.

(Received for publication March 3, 1977; revision accepted August 15, 1977.) 